\title{
A Methodology to Calculate the Supply and Demand Balance by Region for Vietnam's Energy Systems
}

\author{
Nam Hoai Nguyen, Tu Tat Le, Binh Van Doan, Anh Hong Nguyen, Thanh Quyet Doan \\ Institute of Energy Science, Vietnam Academy of Science and Technology, Hanoi, Vietnam
}

\begin{abstract}
The energy supply and demand balance is one of the important issues to address when proposing options for energy system development. Currently, several tools are utilized for calculating the supply and demand balance for Vietnam's energy systems. These tools are instrumental in developing the national energy system. However, most of them treat the national energy system as a unified whole, with no specific focus on regional energy supply and demand balances. This paper presents a methodology to calculate the supply and demand balance for Vietnam's energy systems by region, with the practical application of Corrective Module1, a piece of software which is a result of the joint research and development effort by the Institute of Energy Science, Vietnam Academy of Science and Technology (VAST) and the Melentiev Energy Systems Institute, Siberian Branch of the Russian Academy of Sciences (RAS). The findings of this study demonstrate that the energy system supply and demand balance calculated by region is the scientific basis for researchers, managers, and policymakers to get a clear vision of possible energy system development at the national and regional scale and to provide directions and policies that are consistent with the conditions of each region and the country. This approach is appropriate for Vietnam's geographical conditions, infrastructure, energy resources, load distribution, and policy framework.
\end{abstract}

Index Terms - energy supply and demand balance, energy system, software package, environment

\footnotetext{
* Corresponding author.

E-mail: vanthu@ies.vast.vn
}

http://dx.doi.org/10.38028/esr.2020.02.0005

Received January 20, 2020. Revised April 29, 2020.

Accepted July 11, 2020. Available online October 21, 2020.

This is an open access article under a Creative Commons Attribution-NonCommercial 4.0 International License.

C) 2020 ESI SB RAS and authors. All rights reserved.

\section{INTRODUCTION}

The supply and demand balance is one of the important issues in the energy system (ES) optimization. Results of the supply and demand balance calculation provide inputs enabling researchers to select and propose energy system development options that are suitable, economically feasible, and environmentally sustainable. They provide the scientific basis for assessing the structure, utilization factor, and capacity of fuel/energy sources, and involve the stages of mining, exploitation, processing, conversion, importation, exportation, and consumption. Moreover, these data are instrumental in assessing the substitution of each fuel and energy source in the system to achieve the highest economic and energy efficiency.

\section{LITERATURE REVIEW}

calculation of the ES supply and demand balance requires dedicated software. The software will model the ES as mathematical expressions and equations, and solve the problem of balancing supply and demand in line with the optimal planning methods. Currently, several software packages are used across the world, depending on the objectives and characteristics of each country. Researchers in Vietnam use some of the software packages in developing the long-term ES development strategy. These are MESSAGE, LEAP, MARKAL, EFOM-ENV, and TIMES $[1,2,3,4,5]$.

MESSAGE (Model of Energy Supply Strategy Alternatives and General Environmental Impacts) is provided by the International Atomic Energy Agency (IAEA) to support energy analysis and planning in the member states. MESSAGE describes the ES according to the energy flows from exploitation, processing, and production to consumption as objective functions and constraints. It solves the problem of the supply and demand balance by linear programming methods [1]. This software does not support the evaluation of the strengths and weaknesses of the region as part of the country in the overall development of the national ES.

LEAP (Long-Range Energy Alternatives Planning System), developed by the Stockholm Environment 
Institute, is the analytical tool for energy development scenarios that address environmental issues. This software is widely used by thousands of organizations in more than 190 countries around the world at different levels, including the levels of the city, state, national, regional, and global [2]. However, the software requires detailed information on all employed energy technologies, which is difficult to implement in a developing country with a limited budget and human resources. Therefore, in Vietnam, this program is only applied at the national scale due to insufficient data on energy technologies.

MARKAL was developed by the International Energy Agency back in the 1980s for modeling the energy sector at the levels ranging from local to national. The key objective of MARKAL is to analyze and plan the energy system according to the least-cost approach [3]. MARKAL can be regarded as the prototype model for the energy sector, from which other complex and integrated models were developed.

EFOM-ENV was developed by the European Commission to explore the energy supply, subject to technical, environmental, and political constraints. The strength of EFOM-EVN lies in its ability to integrate renewable technology and calculate emission reduction, thus supporting the development of energy and environment policy. Similar to MARKAL, EFOMENV employs the least-cost criterion for a mix of energy conversion technologies to meet energy demand over the period considered. However, it covers both the energy production and consumption sectors [4]. Given that the environmental data on Vietnam's energy production and consumption are not fully covered in available studies, it proves unfeasible to collect the data and apply this model in the current situation.

TIMES (The Integrated MARKAL - EFOM System) is developed by the International Energy Agency (IEA) with the main objective of analyzing the potential development of energy technologies and fuel resources. TIMES describes the ES in terms of production technologies, conversion, and energy consumption; it calculates and compares scenarios based on the minimum cost. This software can be employed to study energy development at the national or regional scale by means of describing thousands of technologies for energy production, conversion, transportation, and consumption [5]. However, the development of constraints and classification of demand is complicated and requires much effort, which is unsuitable in the context of Vietnam.

Currently, the application of these software packages in Vietnam is limited to the studies that deal with the national scale. Moreover, analyzed energy technologies include only the key ones adopted in some industries and economic sectors. The obtained results lay the foundation for studies and development of the national ES. Meanwhile, there are differences in resource distribution, formation, development level, technical capability, and financial and economic conditions across regions in Vietnam, which generates the need to divide the ES into regions to accommodate region-specific conditions. The regional division of the ES fits the governmental plan of economic development with its division of the whole country into key social and economic regions. As a result, we propose studying and developing a model for the ES supply and demand balance calculation by region to describe the national ES in a way suitable for individual regions' current conditions and future development of Vietnam's economy.

The division of the ES into energy regions will allow both the modeling to be conducted at the national scale and the detailed results to be produced for the regions. The results of the energy supply and demand balance calculation by region will provide the information for assessing the scale, development, and structure of the mix of fuels and energy sources, hence meeting the demand of each region and being consistent with the overall development context of the national ES. The study will propose methods for modeling and solving the problem of Vietnam's ES supply and demand balance by region, which are implemented as the Corrective Module 1 software package[6]. The model is capable of describing the ES regardless of the number of regions, provided that the number of regions is more than one. This is the result of cooperative research between the Institute of Energy Science (VAST) and the Melentiev Energy Systems Institute (RAS) in 2011-2015.

By analyzing the characteristics of the primary social and economic regions, the ES structure, and some other related issues, we proposed calculating Vietnam's ES supply and demand balance in 2015-2030 for eight regions [7]. The region was established based on six economic regions, with the division of two economic regions, including the North and Central Coast regions, into four. Thus, eight energy regions are the Red River Delta (V1), Northeast (V2), Northwest (V3), North Central (V4), the South Central Coast (V5), Highlands (V6), Southeast (V7), and Mekong Delta (V8).

Input data include energy supply (costs and volume of production, imports, and exports), conversion and transportation of energy, energy consumption by type of fuel/energy source (Figure 1,) including coal, oil and gas, and power systems $[8,9,10,11]$. Specifically, the regional parameters of production capacity, costs of production, transportation capacity, transportation costs are set based on the data from individual production and transportation facilities. The data on regional energy consumption are extracted and calculated with respect to the energy consumption of five key economic sectors, namely, industry, agriculture, transportation, tertiary sector, and households. The export/import data are retrieved from global price forecasts.

\section{METHODOLOGY}

A methodology for calculating Vietnam's ES supply and demand balance by region is proposed based on the study of the basic characteristics of the ES and its 
internal and external relations. The methodology covers a comprehensive model of the region, models of subsystems (coal, oil, gas, electricity), objective functions, and constraints. The problem of calculating the supply and demand balance is solved by the linear programming method.

\section{Modelling methodology}

Each region is modeled according to three main factors, including inputs (energy production, imports, and transregional transportation [transportation between regions], conversion and regional transportation [refineries, gas processing, power generation, and regional transportation (transportation within one region)], and outputs (energy to meet regional demand, energy transportation to other regions). The regions are connected through trans-regional transportation, which makes up the comprehensive (national) ES.

The overall regional modeling of ES is based on modeling of three sectoral subsystems, including coal, oil and gas, and power systems of the region. Figure 1 presents the model of Vietnam's ES for one region.

With regards to the coal system, the inputs include coal produced in the region, coal delivered from other regions, and imported coal; conversion and regional transportation include thermal power plants using coal and coal transportation in that region; the outputs include coal supplied to that area, transportation to other regions, and export.

For the oil and gas system, the inputs include crude oil and natural gas produced in the region, petroleum products imported and transported from other regions; conversion and regional transportation include refineries, gas processing, power plants using gas and oil, and their transportation in that region; outputs include crude oil, gas and refined petroleum products consumed in that region, transportation to other regions, and exports.

With regards to the electric system, the inputs include power from hydropower plants and renewable energy production in that region, the fuel type for thermal power, transportation from other regions, imports; conversion and regional transportation include the thermal power plant and power transportation in the region; outputs include power demand in that region, power transportation, and export to other areas.

In Figure 1, all three subsystems of coal, oil, and gas, and electric power are linked to the supply and demand of a regional energy system. The connection among regions through road transportation will constitute overall Vietnam's ES.

The ES modeling diagram allows the construction of the objective function and constraints to solve optimization problems to develop Vietnam's ES by linear planning methodology.

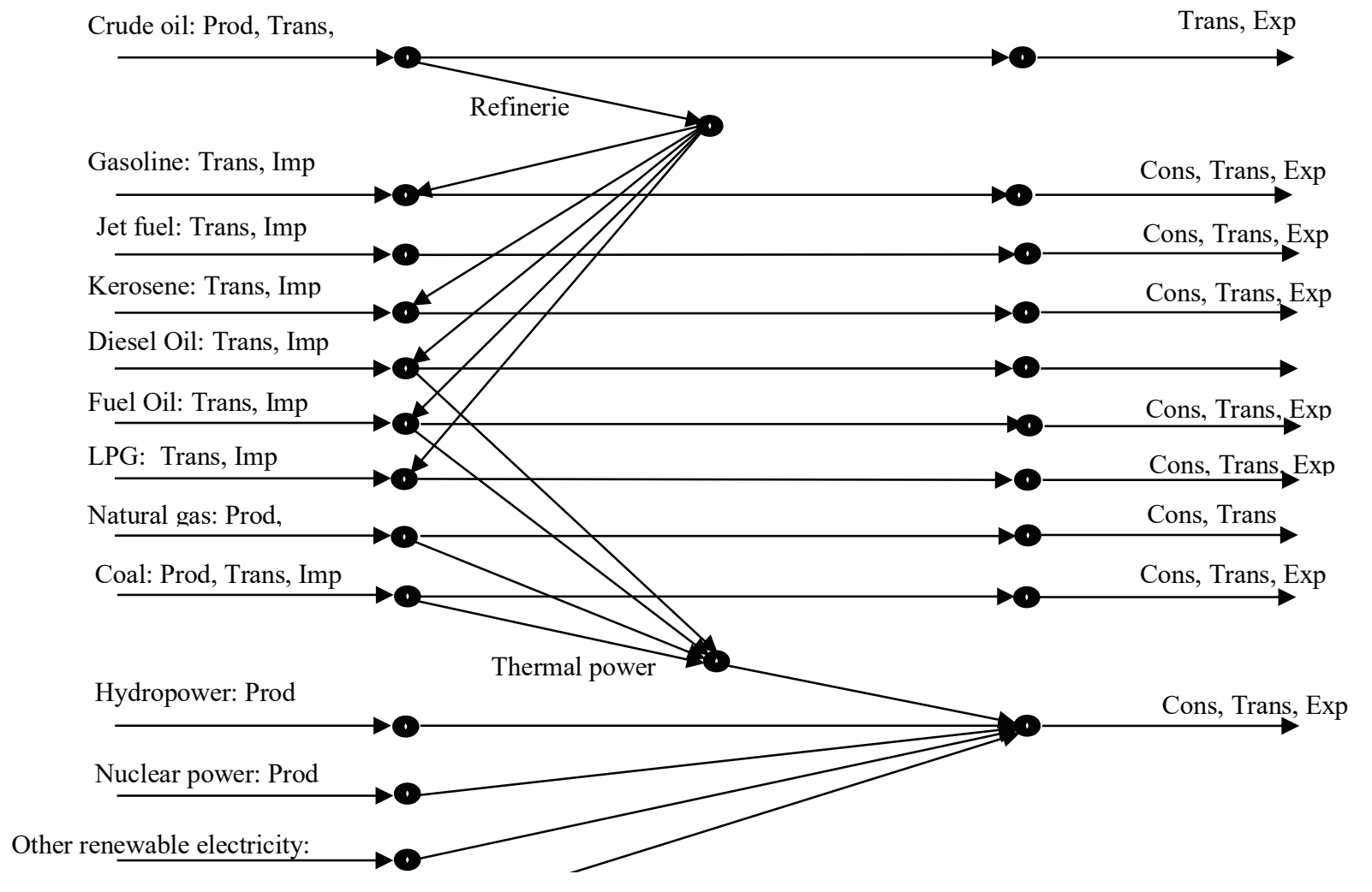

Electricity: Trans, Imp

Figure 1. Modeling of Vietnam's ES by region; Prod: Production; Trans: Transportation; Imp: Import; Exp: Export; Cons: Consumption; Nu: nuclear power; RE: Renewable energy; Nat: Natural gas 


\section{Objective function}

$$
\begin{aligned}
& \sum_{i=1}^{I}\left[\sum_{j=1}^{J} c_{\mathrm{ij}}^{n \ln l} \cdot Q_{\mathrm{ij}}^{n \ln l}+\sum_{k=1}^{K} c_{i k}^{p d} \cdot E_{i k}^{p d}+\sum_{l=1}^{L} c_{i l}^{v t} \cdot F_{i l}^{v t}+\right. \\
& \left.+\sum_{m=1}^{M} c_{i m}^{p x k} \cdot F_{i m}^{p x k}+\sum_{n=1}^{N} c_{i n}^{p n d} \cdot F_{i n}^{p n d}\right] \rightarrow \min
\end{aligned}
$$

Where:

$c_{i j}^{n \ln l}, Q_{i j}^{n \ln l}$ is the cost ratio of fuel/energy source and production volume (excluding power), USD/KTOE

$c_{i k}^{p d}, E_{i k}^{p d}$ is the cost ratio of fuel/energy source and production volume, USD/KTOE

$c_{i l}^{v t}, F_{i l}^{v t}$ is the cost and volume of transportation of fuels/ energy sources, USD/KTOE

$c_{i m}^{p x k}, F_{i m}^{p x k}$ is the calculated cost ratio and export volume that can be met, USD/KTOE

$c_{i n}^{p n d}, F_{i n}^{p n d}$ is the calculated cost ratio and domestic demand that can be met, USD/KTOE

$I$ is the number of geographical energy regions

$J$ is the number of types of fuel/energy sources (excluding electrical power)

$K$ is the number of inputs for power generation, including hydropower and renewable energy

$L, M, N$ is the number of $N \ln L$ transportations of fuel/ energy sources (including electrical power).

\section{Constraints}

The energy demand and supply balance constraints of the region, including production, transportation, import, and export constraints:

- The constraints of the energy demand and supply balance of the region include the constraints on the power demand and supply balance and the balance of energy demand for other needs.

+ the fuel and energy balance for other needs in the regions:

$$
Q_{s x}^{n \ln l}+Q_{v t v}^{n \ln l}-Q_{v t r}^{n \ln l}-Q_{p d}^{n \ln l}-D_{n c k}^{n \ln l} \geq 0
$$

Where:

$Q_{s x}^{n \ln l}$ is fuel/energy produced in the region, KTOE

$Q_{v t v}^{n \ln l}$ is the fuel/energy transported to the region (including domestic transportation and import), KTOE

$Q_{v t r}^{n \ln l}$ is the fuel/energy transported from the region (including domestic transportation and exports), KTOE

$Q_{p d}^{n \ln l}$ is the fuel/energy for power generation in the region, KTOE

$Q_{n c k}^{n \ln l}$ is the fuel/energy for other needs of the region, KTOE

The number of constraints equals the total number of types of fuel/energy sources (excluding power), multiplied by the number of regions.
+ regional power balance:

$$
E_{s x}^{d n}+E_{v t v}^{d n}-E_{v t r}^{d n}-E_{n c}^{d n} \geq 0
$$

Where:

$E_{s x}^{d n}$ is power generated in the region, including all types of power plants, KTOE

$E_{v t v}^{d n}$ is power transported to the region, including domestic transportation and import, KTOE

$E_{v t r}^{d n}$ is power transported from the region, including domestic transportation and export, KTOE

$E_{n c}^{d n}$ is the power demand in the region, KTOE

The number of constraints equals the number of regions. production, transportation, import, and export constraints:

$$
0 \leq Q_{s}^{n \ln l} \leq Q_{\max }^{n \ln l}(4)
$$

Where:

$Q_{s}^{n \ln l}$ is the required volume of fuel/energy source, KTOE $Q_{\max }^{n \ln l}$ is the upper boundary of the required fuel/energy source volume, KTOE

This constraint is used for all types of fuel/energy sources at all stages of production, import, export, and transportation. The number of constraints equals the number of produced fuels/energy sources + the number of energy transportations $\mathrm{x}$ types of transportation + the number of energy exports $x$ types of exports + the number of energy imports $x$ types of imports.

Power generation, import, and export constraints:

where:

$$
0 \leq E_{s}^{d n} \leq E_{\max }^{d n}
$$

$E_{s}^{d n}$ is the volume of required electrical power, KTOE $E_{\max }^{d n}$ is the upper boundary of required power, KTOE

These constraints are used for all types of power plants, except for transported, imported, and exported power calculated inclusively. The number of constraints equals the number of power plants + the number of domestic electrical power transportations + the number of imported power transportations + the number of exported power transportations.

Transportation means transportation equivalent between two regions or between a region and an importing or exporting country. For example, power transmission from region 1 to region 2 is performed through numerous lines; however, in this model, only one transportation equivalent is calculated.

\section{CALCULATION RESUlTS FOR VIETNAM'S ENERGY SYSTEMS}

collected data are entered into the Corrective - Module1 software package, and Vietnam's ES supply and demand balance for the year 2020 is calculated as the reference case. Calculation results are presented by type of fuel/ energy sources, with two Tables of results for each type (the Table of overall results and the Table of the fuel/energy 
transportation). In the case of electrical power, three tables are the table of overall results, the table for electricity transmission and, the Table of electricity generation by types of power plants. Types of fuel/energy sources with two tables of results are anthracite, lignite, natural gas, crude oil, liquefied petroleum gas, gasoline, oil, fuel oil, kerosene, jet fuel, and biomass. These types of fuel/energy sources have a similar structure of the result Table, as is shown in Table 1.

Table 1. Supply and demand balance of coal in 2020 Reference case (KTOE)

Table 1 presents the supply and demand balance of coal in 8 regions. The total production, import, export, and consumption of the whole country is the sum of the corresponding values of 8 regions. The main difference is the detailed results for each region. Coal is produced in region 2. In 2020, it needs to be imported into V4, V5, and V8. The difference between the transportation to and from the region illustrates the transported energy used within the region or the destination of energy transportation.

Table 2. Transportation of coal in 2020 - Reference case (KTOE)

The coal is transported from region 2 to region 1; after satisfying the needs of region 1 , the remaining coal will be transported to region 3 and region 4 . Coal is imported into region 4 . Thus, the imported coal, in addition to domestic coal, will enable region 4 to meet its demand. The remaining coal will be transported to region 6 . Signs of the values in Table 2 stand for the transportation direction (to be read as the «column» to «row» direction). For example, transportation from V1 to V2 is 15.937 .8 (positive), while transportation from $\mathrm{V} 2$ to $\mathrm{V}$ is -15.937 .8 (negative).

Similar Tables of results can be obtained for other types of fuel/energy sources such as gas, crude oil, refined petroleum products, renewable energy, and electricity. For electric power, apart from the two Tables that are similar to those used for coal, there are detailed results of electricity generation for different types of power plants (Table 3 ).

Table 3. Electricity generation by type of power plants in 2020 - Reference case (GWh)

Table 3 indicates that Vietnam possesses diverse resources for electricity generation, where coal, gas, and hydropower account for the largest share of $39.49 \%$, $26.55 \%$, and $29.28 \%$, respectively. The share of renewable energy resources such as wind, solar, and biomass in the energy mix is very small $-0.82 \%, 0.01 \%$, and $0.32 \%$, respectively. Power output is evenly distributed between regions, ranging from $7 \%$ to $18 \%$, while region 2 holds the largest share (18\%), and region 6 has the smallest share $(7 \%)$. The results of the ES supply and demand balance calculation by region provide the same amount of information as those obtained with the aid of other software packages. Moreover, we get detailed results for each region, which assists the assessment of capacity, role, advantages, and limitations of the regions in the energy production and supply.

\section{DISCUSSION}

\section{Discussion of calculation results}

The modeling and solving the problem of the energy supply and demand balance provide not only overall results applicable to the national scale but also detailed results by region in terms of the ES capacity and structure required to meet the regional and national demand while being suitable for the conditions specific to each region and consistent with the overall development context of the national ES.

The total volume of domestic coal production in 2020 is $27492.3 \mathrm{KTOE}$, which is exported from region 2 to meet the national demand. Moreover, three regions, including V4, V5, and V8, need to import coal. Regarding transportation, coal is transported from region 2 to region 1 .

Table 1. Supply and demand balance of coal in 2020 - Reference case (KTOE)

\begin{tabular}{|c|c|c|c|c|c|c|c|c|c|c|}
\hline \multirow{2}{*}{$\begin{array}{l}\text { Types of power } \\
\text { plants }\end{array}$} & \multicolumn{8}{|c|}{ Region } & \multirow{2}{*}{ Total } & \multirow{2}{*}{ Share } \\
\hline & V1 & V2 & V3 & V4 & V5 & V6 & V7 & V8 & & \\
\hline $\begin{array}{l}\text { Anthracite-fired } \\
\text { thermal power } \\
\text { plant }\end{array}$ & 32120.0 & 42470.0 & 0.0 & 20000.0 & 1106.8 & 0.0 & 1860.0 & 3766.4 & $101,323.2$ & $\begin{array}{r}39.49 \\
\%\end{array}$ \\
\hline $\begin{array}{l}\text { Brown coal-fired } \\
\text { thermal power } \\
\text { plant }\end{array}$ & 0.0 & 0.0 & 0.0 & 1855.4 & 0.0 & 0.0 & 0.0 & 0.0 & 1855.4 & $0.72 \%$ \\
\hline $\begin{array}{l}\text { Gas turbine } \\
\text { power plant }\end{array}$ & 150.0 & 0.0 & 0.0 & 0.0 & 2475.0 & 0.0 & 32240.4 & 33252.1 & 68117.5 & $\begin{array}{r}26.55 \\
\% \\
\end{array}$ \\
\hline Hydropower & 0.0 & 2669.3 & 30526.7 & 6264.3 & 12216.1 & 18546.4 & 4909.2 & 0.0 & 75132.0 & $\begin{array}{r}29.28 \\
\% \\
\end{array}$ \\
\hline Wind power & 0.0 & 0.0 & 0.0 & 100.0 & 1065.0 & 0.0 & 300.0 & 630.0 & 2095.0 & $0.82 \%$ \\
\hline Solar power & 0.0 & 5.5 & 5.0 & 2.0 & 1.3 & 6.4 & 3.8 & 13.3 & 37.2 & $0.01 \%$ \\
\hline Biomass power & 55.7 & 31.4 & 15.5 & 162.3 & 91.2 & 50.2 & 122.0 & 301.7 & 830.0 & $0.32 \%$ \\
\hline Nuclear power & 0.0 & 0.0 & 0.0 & 0.0 & 7200.0 & 0.0 & 0.0 & 0.0 & 7200.0 & $2.81 \%$ \\
\hline Total & 32325.7 & 45176.1 & 30547.2 & 28384.0 & 24155.4 & 18602.9 & 39435.5 & 37963.5 & 256590.3 & \\
\hline Share & $13 \%$ & $18 \%$ & $12 \%$ & $11 \%$ & $9 \%$ & $7 \%$ & $15 \%$ & $15 \%$ & & \\
\hline
\end{tabular}


Table 2. Transportation of coal in 2020 - Reference case (KTOE)

\begin{tabular}{ccccccccccc}
\hline \hline Region & V1 & V2 & V3 & V4 & V5 & V6 & V7 & V8 & Imports \\
\hline V1 & 0.0 & -15937.8 & 709.3 & 4649.8 & 0.0 & 0.0 & 0.0 & 0.0 & 0.0 \\
\hline V2 & 15937.8 & 0.0 & 0.0 & 0.0 & 0.0 & 0.0 & 0.0 & 0.0 & 0.0 \\
\hline V3 & -709.3 & 0.0 & 0.0 & 0.0 & 0.0 & 0.0 & 0.0 & 0.0 & 0.0 \\
\hline V4 & -4649.8 & 0.0 & 0.0 & 0.0 & 0.0 & 354.3 & 0.0 & 0.0 & 4373.9 \\
\hline V5 & 0.0 & 0.0 & 0.0 & 0.0 & 0.0 & 0.0 & 0.0 & 0.0 & 967.7 \\
\hline V6 & 0.0 & 0.0 & 0.0 & -354.3 & 0.0 & 0.0 & 0.0 & 0.0 & 0.0 \\
\hline V7 & 0.0 & 0.0 & 0.0 & 0.0 & 0.0 & 0.0 & 0.0 & -2202.4 & 0.0 \\
\hline V8 & 0.0 & 0.0 & 0.0 & 0.0 & 0.0 & 0.0 & 2202.4 & 0.0 & 4210.2 \\
\hline \hline
\end{tabular}

Table 3. Electricity generation by type of power plants in 2020 - Reference case (GWh)

\begin{tabular}{|c|c|c|c|c|c|c|c|c|c|c|}
\hline \multirow{2}{*}{$\begin{array}{l}\text { Types of power } \\
\text { plants }\end{array}$} & \multicolumn{8}{|c|}{ Region } & \multirow{2}{*}{ Total } & \multirow{2}{*}{ Share } \\
\hline & V1 & $\mathrm{V} 2$ & V3 & V4 & V5 & V6 & V7 & $\mathrm{V8}$ & & \\
\hline $\begin{array}{c}\text { Anthracite-fired } \\
\text { thermal power } \\
\text { plant }\end{array}$ & 32120.0 & 42470.0 & 0.0 & 20000.0 & 1106.8 & 0.0 & 1860.0 & 3766.4 & $101,323.2$ & $\begin{array}{r}39.49 \\
\%\end{array}$ \\
\hline $\begin{array}{c}\text { Brown coal-fired } \\
\text { thermal power } \\
\text { plant }\end{array}$ & 0.0 & 0.0 & 0.0 & 1855.4 & 0.0 & 0.0 & 0.0 & 0.0 & 1855.4 & $0.72 \%$ \\
\hline $\begin{array}{l}\text { Gas turbine } \\
\text { power plant }\end{array}$ & 150.0 & 0.0 & 0.0 & 0.0 & 2475.0 & 0.0 & 32240.4 & 33252.1 & 68117.5 & $\begin{array}{r}26.55 \\
\% \\
\end{array}$ \\
\hline Hydropower & 0.0 & 2669.3 & 30526.7 & 6264.3 & 12216.1 & 18546.4 & 4909.2 & 0.0 & 75132.0 & $\begin{array}{r}29.28 \\
\% \\
\end{array}$ \\
\hline Wind power & 0.0 & 0.0 & 0.0 & 100.0 & 1065.0 & 0.0 & 300.0 & 630.0 & 2095.0 & $0.82 \%$ \\
\hline Solar power & 0.0 & 5.5 & 5.0 & 2.0 & 1.3 & 6.4 & 3.8 & 13.3 & 37.2 & $0.01 \%$ \\
\hline Biomass power & 55.7 & 31.4 & 15.5 & 162.3 & 91.2 & 50.2 & 122.0 & 301.7 & 830.0 & $0.32 \%$ \\
\hline Nuclear power & 0.0 & 0.0 & 0.0 & 0.0 & 7200.0 & 0.0 & 0.0 & 0.0 & 7200.0 & $2.81 \%$ \\
\hline Total & 32325.7 & 45176.1 & 30547.2 & 28384.0 & 24155.4 & 18602.9 & 39435.5 & 37963.5 & 256590.3 & \\
\hline Share & $13 \%$ & $18 \%$ & $12 \%$ & $11 \%$ & $9 \%$ & $7 \%$ & $15 \%$ & $15 \%$ & & \\
\hline
\end{tabular}

After satisfying the needs of region 1, it will be transported to region 3 and region 4 . Imported coal and domestic coal ensures that region 4 meets its demand for coal. The remaining coal will be used in region 6 .

These results are essential for planning regional energy development and identifying regional energy demand, production, transportation, and imports. Moreover, these results can be used to evaluate the contribution of each region (in cooperation with other regions) to the overall energy supply and demand balance through the amount of energy transported to and from each region. On the national scale, in addition to the information on the structure and makeup of energy production, imports, and exports, these data provide some details on energy imports and show which region is the most economical and efficient in terms of energy import. Moreover, a comparison of different development scenarios allows identifying the location for new energy projects to achieve the most efficient implementation.

With regard to power systems, they are complex and play an essential role in the energy system. Their capacity and structure directly influence the development of the coal and gas industries as these two industries contribute the majority of raw materials to electricity generation. The calculation results show that all regions generate electricity, but there is a difference in the resources used for electricity generation, depending on the potential and capacity of each region. The regions vary in demand for electricity, which requires its transmission. Regions 2, 3,4 , and 5 generate a sufficient amount of electricity to satisfy internal demand and supply it to other regions. At the same time, regions 1 and 7 mainly receive electricity from other areas.

Results of the electricity supply and demand balance calculation are instrumental in assessing the scale and structure of power plants in each region. For example, region 3 hosts many hydropower plants, while the electricity demand is low there; therefore, there is no need to build large thermal power plants in this region. Meanwhile, region 2 has large coal reserves, which is a favorable condition for building large coal thermal power plants. Region 1 has a high electricity demand, and its natural characteristics are suitable only for developing thermal power; therefore, the volume of transported electricity is large. This allows developing a specific regional plan based on its capacity. On the national scale, 
the results are supportive of the priority of power plants, their capacity, and their location. Thus, the results of the regional supply and demand balance calculation will serve as the scientific basis to assist scientists, managers, and policymakers in getting a clear outlook of the potential to develop the ES not only on the national scale but also on the regional one, which can underlie suitable and efficient regional policies.

\section{Preliminary evaluation of the proposed methodology}

Based on the evidence provided by the analysis and study of the situation, along with the calculations of the development plan, we state that the model needs to be revised and completed with respect to modeling the transportation system and integrating environmental emissions. As to the transportation system description, this model describes the new transportation system between two regions by a single transportation line. In fact, there are five existing lines of energy transportation in Vietnam, including waterway, railway, road, pipeline, and power transmission line transportation. Therefore, a single transportation line is inadequate and needs to be supplemented by other transportation lines in the model. Moreover, the cost of local transportation is not fully described due to the incompleteness of the database on types of energy sources, transporting distance, load distribution, and others.

In terms of the environmental aspect of the ES, while the environmental standards and regulations are available for the design and construction of energy systems and power projects, there is no constraint on the environment integrated into the model. There is a need for further research to incorporate environmental impacts, specifically environmental emissions of energy systems into the model.

\section{CONCLUSION}

Simulation and calculation of the ES supply and demand balance by region is an appropriate approach consistent with the natural geographical conditions, economic and engineering infrastructure, energy resource potential, load distribution, and development policies of Vietnam in the current context. This model is capable of handling any number of regions greater than one. The modeling results will serve as the scientific basis for scientists, managers, and policymakers to enable them to get a clear perspective on the possibility of developing the ES on the national and regional scales. Some issues, however, need further research, including regional and trans-regional transportation systems and environmental emissions.

\section{ACKNOWLEDGMENT}

The authors would like to thank the VAST Institute of Energy Science, experts from the Melentiev Energy Systems Institute, Siberian Branch of the Russian Academy of Science, the authorities, and colleagues who have created favorable conditions for us to perform this study.

\section{REFERENCES:}

[1] IAEA, 2009, IAEA Tools and Methodologies for Energy System Planning and Nuclear Energy System Assessments.

[2] SEI, 2008, An Introduction to LEAP IAEA, available online: $\quad$ http://www.energycommunity.org/default. asp?action $=47$

[3] Morris S.C., Lee J., Goldstein G., 1993, Results from the US Markal Model, Stanford University.

[4] Beeck N., 1999, Classification of Energy models, Tilburg University.

[5] Noble-Soft Systems Pty Ltd, 2014, ANSWER-TIMES "Getting Started" Manual.

[6] Alexei V. Edelev, Nguyen Quang Ninh, Nguyen Van The, Tran Viet Hung, Le Tat Tu, Doan Binh Duong, Nguyen Hoai Nam, 2012, Developing "Corrective" software: 3-region model, Proceedings of International Conference Green Energy and Development, Hanoi, Vietnam, 41-52.

[7] The Government Decree No. 92/2006/NĐ-CP dated September 7, 2006, On preparing, approving, and managing the master plan of social and economic development. (in Vietnamese)

[8] Vietnam Coal and Mining Group, 2014. The Master plan of coal industry development to 2020, with a view to 2030 (Revised).

[9] Petrol Vietnam, 2005, Strategy on petroleum industry development to 2015, with a view to 2025 .

[10] Electricity Vietnam, 2011, The master plan of national power sector development in 2011-2020, with a view to 2030

[11] APEC, Energy database, available online: http:// www.ieej.or.jp/egeda/database/database-menu2.html 